\title{
Challenges for Cancer Care Delivery to Adolescents and Young Adults: Present and Future
}

\author{
Mathew R. Meeneghan William A. Wood \\ Lineberger Comprehensive Cancer Center, University of North Carolina, Chapel Hill, N.C., USA
}

\section{Key Words}

Adolescents and young adults · Hematological malignancy

\begin{abstract}
Adolescents and young adults occupy a unique place within the cancer community due to the challenges they face related to disease biology, access to care, and psychosocial and socioeconomic circumstances. Efforts to define specific needs and targets for intervention in these areas are under way and evolving. This review will discuss the current and future challenges in delivering quality care to this population.

(c) 2014 S. Karger AG, Basel
\end{abstract}

\section{Introduction}

Cancer in the adolescent and young adult (AYA) population is the most common cause of nonaccidental death following injuries, suicide and homicide $[1,2]$ with up to a third of cases coming from hematological malignancies (table 1) [2, 3]. AYAs have been recognized as a distinct population within the oncology community due to the unique challenges they face. When compared to pediatric and older adult oncology patients, these 15- to 39-year- olds encounter differences in disease biology, access to care, psychosocial and socioeconomic circumstances, and issues related to long-term follow-up [4-6]. Furthermore, there have been fewer improvements in treatment of AYA cancers than have been observed in non-AYA populations, a trend that is evident across all ethnic groups and tumor types [2]. Current reports place the 5-year overall survival for AYAs with hematological malignancies between 47 and 95\% [7]. There have been efforts to define specific needs and targets for intervention in order to achieve high-quality care for AYAs. The National Comprehensive Cancer Network has recently published guidelines to address this [8].

The spectrum of malignant diseases varies among different age groups. Pediatric oncological diseases are predominated by embryonal-type tumors such as Wilms' tumor, neuroblastoma, hepatoblastoma and acute lymphoblastic leukemia (ALL). In contrast, adult cancer diagnoses tend to come from epithelial origin such as breast, lung and prostate tissue. AYAs straddle these two groups, sharing overlaps in terms of age and tumor type; however, the prognosis of a given tumor type may be significantly different when compared to non-AYAs. For instance, the outcomes of AYAs with ALL are worse than those of pediatric patients [9].

\section{KARGER}

E-Mail karger@karger.com

www.karger.com/aha (c) 2014 S. Karger AG, Basel

0001-5792/14/1324-0414\$39.50/0
Mathew R. Meeneghan

Division of Hematology/Oncology, Physicians Office Building

170 Manning Drive Campus, Box 7305

Chapel Hill, NC 27599-7305 (USA)

E-Mail meeneghan@gmail.com 
Table 1. Percentage of all cancer diagnoses [adapted from Bleyer et al. 2]

\begin{tabular}{llll}
\hline Disease & $\begin{array}{l}\text { Aged } \\
15-19, \%\end{array}$ & $\begin{array}{l}\text { Aged } \\
20-29, \%\end{array}$ & $\begin{array}{l}\text { Aged } \\
30-39, \%\end{array}$ \\
\hline Hodgkin's lymphoma & 15 & 10 & 3 \\
Non-Hodgkin's lymphoma & 7 & 6 & 6 \\
Acute lymphoblastic leukemia & 7 & 2 & 1 \\
Acute myeloid leukemia & 5 & 3 & 1 \\
\hline
\end{tabular}

Other papers have discussed how diverse and incompletely understood disease biology can explain how the same pathological diagnosis can have different courses in different age groups [5]. The purpose of this article is to discuss the nonpathological issues that create challenges in achieving satisfactory care delivery for AYAs with a focus on hematological malignancies.

\section{Access to Clinical Trials and Initiation of Treatment}

The main method by which the field of medicine advances is careful scientific study of disease. Detailed analysis of various interventions through clinical trials informs the medical community of the proper way to best improve outcomes. Unfortunately, cancer patients between the ages of 15 and 35 have the lowest rates of accrual to clinical trials [10]. Roughly $90 \%$ of patients under the age of 15 are managed at institutions with trials sponsored by the National Cancer Institute, and most of those patients are entered into trials. These numbers drop off rapidly for older patients. Only $20-35 \%$ of 15 - to 19 -yearolds are seen at such institutions, and only $10 \%$ go on trial. For 20- to 29 -year-olds, less than $10 \%$ are seen at institutions with trials sponsored by the National Cancer Institute, and only $1 \%$ are actually enrolled. Including community settings, rates of enrollment for pediatric populations are around $60 \%$. In older adults with cancer, enrollment falls in the 3-5\% range [10]. The overall rate for enrollment of AYAs in clinical trials is estimated to be less than 2\% [2]. Within the AYA group, clinical trial enrollment for hematological malignancies seems to worsen with age. Liu et al. [11] found that when compared to patients younger than 15 years, patients aged 15-19 were $48 \%$ less likely to enroll in leukemia trials and $62 \%$ less likely to enroll in lymphoma trials. Meanwhile patients aged 20-44 accrued to clinical trials at a rate of $91-96 \%$ lower than patients aged $<15$ years for all leukemias [12].
Similar evidence of poor trial enrollment has been noted for older AYAs with lymphoma [13].

Reasons for lower clinical trial enrollment are likely multifaceted. Lack of awareness of ongoing trials by treating physicians and patients and lack of willingness of patients to participate in the trials are obvious barriers. In addition, there are simply fewer trials open for the cancers that are common in this age group. Historically, there may also be lack of collaboration between pediatric and adult cooperative groups, resulting in trials designed for older or younger patients, but few specifically designed with AYAs in mind [9]. To combat this, the Children's Oncology Group Adolescent and Young Adult Initiative has been working to increase the age limits on trials that include diseases that also affect AYAs [2]. The Cancer and Leukemia Group B 10403 trial for patients aged 16-39 with newly diagnosed ALL is the first intergroup study designed specifically for AYAs [14].

There may also be economic reasons underlying the low rate of AYA trial enrollment. AYAs are the most uninsured age group, and not every clinical trial covers the complete cost of care [2]. In general, community-based physicians are less likely to enroll AYAs in clinical trials, the reasons for which are variable but may include economic disincentives. Furthermore, providers may lack adequate training in issues specific to the AYA population and thus may not recognize the particular importance of trials in this age group. AYAs may also be perceived by local physicians as a group with a higher likelihood of noncompliance and may thus be considered less suited to clinical trial enrollment [2].

Education and outreach at multiple steps may help to address gaps in enrollment of AYAs into trials [10]. AYAs should be encouraged to ask about clinical trials and to consider traveling to other facilities that have open trials, if possible, since in some instances the standard of care for the AYA population has not been defined and is thus not clear locally. Once enrolled, AYAs should be given adequate support to help them with adherence to the protocol. One example of this strategy is the Children's Oncology Group's Adolescent and Young Adult Initiative which was integral to increasing the upper limit for age in Children's Oncology Group trials as discussed above and continues to collaborate with adult cooperative groups on codevelopment of trials for Hodgkin's lymphoma (HL) and non-HL [2].

From a policy standpoint, it is important to note that the available funding for clinical trials is limited and thus may preclude developing specific trials for the AYA population. In one survey of providers and patients, both 
groups agreed that higher priority is needed for trials that address specific predefined topics as opposed to traditional investigator-initiated studies [15]. This type of strategic prioritization could benefit areas of need such as defining standards of care for AYA hematological malignancies. Additionally, though randomized trials remain the gold standard for developing the evidence base for AYA hematological malignancies, comparative effectiveness research studies may be a helpful and less expensive adjunct to facilitate this goal. Comparative effectiveness research compares the effectiveness of tests, treatments, procedures or other health care services in multiple formats, such as prospective data collection or systematic reviews [16]. The goal of comparative effectiveness research is to improve health care by studying 'real-world' data, which is particularly applicable to AYAs with leukemias and lymphomas as this population may be treated in both pediatric and adult settings [17].

\section{Access to Multidisciplinary Professionals Well Versed in Specific Issues in the AYA Population}

The majority of 15- to 19-year-old patients are referred to adult oncologists [10]; however, this practice pattern does vary with disease pathology. Cases of acute leukemia tend to get referred to pediatric oncologists, while lymphomas tend to get referred to adult oncologists [9]. The primary goal of treating AYAs should be achieving the best outcome. Some have argued that this may mean treating AYAs with ALL using a pediatric regimen and possibly at a pediatric center, though this is the subject of ongoing debate. In general, issues around which approach and which treatment setting are optimal for AYA hematological malignancies remain largely unresolved and deserve further specific attention [10]. In addition to making sure AYAs receive the best diseasebased care possible, this group of patients also has a large and unique set of psychosocial issues that require diligent attention.

\section{Treatment-Related Issues}

Long-term effects from treatment of AYA hematological malignancies vary by specific treatment-related exposure. Cardiac toxicity is a well-described potential complication of anthracyclines [18], as is the lung toxicity associated with bleomycin used in the treatment of HL [19]. Secondary malignancies including leukemia and lung cancer have been reported after treatment of non-HL [20] and HL [21], whether from primary therapy or from subsequent hematopoietic stem cell transplantation (HSCT) [22]. Long-term infertility (see below) and endocrine dysfunction [23-25] are also prevalent. In the AYA population, physicians must consider these consequences and assume long-term survival of patients when weighing the risks and benefits of competing treatment strategies that may carry different late effect risk profiles. For any given regimen, it is imperative that patients undergo the proper and necessary pretreatment organ function screening and that meticulous detail is paid to proper dosing and supportive care to help mitigate these risks. Having noted that, AYAs tend to be better equipped to tolerate intensive therapies than their older counterparts, even if they have a higher risk of treatment-related complications than pediatric patients treated in a similar way.

Interestingly, technology may prove to be a useful ally in these situations. Patients with chronic diseases are more likely to use the Internet, and cancer patients who research their diseases online are more engaged with their physicians, ask more questions and have more of a partnership in their treatments [26]. Internet use changes how patients cope with and manage their pain [27]. Because most AYAs use smartphones [28] and are generally technology avid, these observations raise the possibility that technology could be used to facilitate communication between AYAs and providers in the areas of patientreported symptoms or management of short- or longterm disease and treatment-related complications.

\section{Fertility}

Infertility is defined as the inability to conceive after 1 year of intercourse without contraception [29]. Unfortunately, infertility can occur as a result of treatment for several of the hematological malignancies in the AYA population. Men can have disease-related infertility, primary or secondary hormonal insufficiency, and treatment-related damage or depletion of germinal stem cells that may or may not resolve after completion of therapy [29]. For women, cancer-directed treatments can decrease primordial follicles, affect hormonal balance or interfere with the function of the ovaries, fallopian tubes, uterus or cervix even if menses do return [29]. Furthermore, premature ovarian failure not only causes infertility but can also lead to vasomotor symptoms and fatigue [30]. AYAs generally regard fertility as important, prefer biological offspring and want to have children in the fu- 
Table 2. Risk of infertility by treatment regimen [adapted from Lee et al. 29 and Levine et al. 32]

\begin{tabular}{|c|c|c|}
\hline Risk & Treatment & Disease \\
\hline High risk $(>80 \%)$ & $\begin{array}{l}\text { Radiation therapy } \geq 10 \text { Gy to ovaries; alkylators } \\
\text { TBI; alkylators } \\
\text { Alkylators }+ \text { TBI } \\
\text { Cyclophosphamide } \geq 7.5 \mathrm{mg} / \mathrm{m}^{2} \text { in women }<20 \text { years old } \\
\text { Procarbazine-containing regimens }\end{array}$ & $\begin{array}{l}\text { HL } \\
\text { BMT } \\
\text { BMT, HL } \\
\text { Non-HL, ALL } \\
\text { HL }\end{array}$ \\
\hline Low risk $(<20 \%)$ & $\begin{array}{l}\text { Multiagent therapy } \\
7+3 \\
\text { CHOP ( } 4-6 \text { cycles }) \\
\text { COP } \\
\text { ABVD }\end{array}$ & $\begin{array}{l}\text { ALL } \\
\text { AML } \\
\text { Non-HL } \\
\text { Non-HL } \\
\text { HL }\end{array}$ \\
\hline
\end{tabular}

ture $[31,32]$. The risk of ovarian failure varies with the type of therapy, dose, duration and age of the patient, but the risk of having at least some posttreatment symptoms is significant [30]. For instance, one survey showed that following stem cell transplantation, all women have at least some postmenopausal symptoms [30].

Fortunately, there are resources available for providers to estimate the risk of infertility based on the sex of the patient and the type of cancer or regimen used. One such website is http://www.fertilehope.org/tool-bar/riskcalculator.cfm, which can be useful when having this discussion during the planning phases of treatment. Table 2 shows similar estimates in tabular form [29]. Education of the oncology medical community is one intervention that offers a chance for great improvement in the fertility preservation of AYAs undergoing cancer treatment [31]. One survey of practitioners showed that while oncologists knew the importance of fertility and were aware of potential adverse effects of alkylators and irradiation, about half of responders were unaware that risks were higher in men, that birth defects and cancer rates in children of cancer survivors are at baseline population levels, and did not know that ovarian cryopreservation is an option in the prepubertal setting. Moreover, $10 \%$ thought sperm banking was not successful enough to be worthwhile. With this knowledge gap, it is not surprising that oncologists have room for improvement when discussing fertility issues with their patients [32].

Further complicating matters, $30-60 \%$ of cancer survivors did not recall getting information about possible infertility issues even when they did receive prior counseling [32].

In addition to problems with awareness and education, there are still limitations related to the availability and efficacy of the techniques used to address fertility preservation. One obvious impediment is cost. As an example, one analysis found that sperm banking cost USD 275 for initiation followed by an ongoing USD 300 annual storage fee [31]. Access to appropriate referral sites and finding an appropriate specialist were also barriers to care $[31,32]$. Some oncologists report that in a busy modern practice there simply is not enough time to address these issues, especially when there are concerns about treatment delay [32].

Finally, there are several ethical issues involved in fertility preservation. Levine et al. [32] and Jadoul and Kim [33] suggest the following examples:

(1) making sure to clarify reasonable expectations for fertility preservation;

(2) distinguish which methods of preservation are standard of care and which are experimental; 
(3) dealing with the consent or assent of patients under 18;

(4) whether or not to delay treatment to allow for preservation, especially experimental ones;

(5) accurate articulation of immediate and long-term financial costs;

(6) consideration of the role of long-term prognosis on the decision to conceive in the first place;

(7) cancer treatment is difficult and can affect relationships; therefore, it may not be the best time to make embryos during this major life stressor.

Keeping the above ethical questions in mind, when considering fertility preservation it is important to remember that treatment of the underlying oncological disease is paramount. Any intervention should minimize harm and avoid delay in disease-directed therapy that would worsen the prognosis. There have been multiple guidelines published on fertility issues in oncology patients [e.g. American Society of Reproductive Medicine Ethics Committee 34; American Society of Clinical Oncology fertility guidelines 35]. Regarding fertility preservation options, men are largely limited to sperm banking, which they should all be offered regardless of the risk of spermatic failure [36]. For women, options include in vitro fertilization, in vitro maturation or oopheropexy to move the ovaries out of a planned field of radiation [33]. Ovarian cortex cryopreservation is another choice that is still experimental. Which of these methods is right for a given woman will depend on the urgency of treatment, age of the patient, marital status, regimen and dose of gonadotoxic drugs [36].

Risks for infertility vary by specific hematological disease and by regimen. For example, one popular standard of care treatment for HL is doxorubicin, bleomycin, vinblastine and dacarbazine (ABVD) which poses little to no risk of premature ovarian failure. A study of 36 female HL survivors who were alive without relapse at least 3 years after completion of ABVD showed that the median time to pregnancy and 12-month pregnancy rates were statistically similar when compared to healthy controls [37]. Neither age at treatment nor the number of cycles (range 2-6) were associated with altered pregnancy rates. In contrast, more aggressive regimens like bleomycin, etoposide, doxorubicin, cyclophosphamide, vincristine, procarbazine and prednisone (BEACOPP) can be more gonadotoxic. The risk of azoospermia following BEACOPP is $90 \%$ [38] and reported rates of birth after natural fertilization by male $\mathrm{HL}$ survivors at $<1 \%$ after BEACOPP as compared to $7.5 \%$ for non-BEACOPP regimens [39]. Likewise for females, rates of birth after BEACOPP were
$6.5 \%$ compared to $16.6 \%$ for non-BEACOPP regimens. It is reasonable in most cases to delay treatment for 1 ovulatory cycle in order to cryopreserve embryos or oocytes [33]. Men can have pretreatment fertility impairment, but sperm banking should still be offered [40].

ALL and acute myeloid leukemia protocols attempt to preserve fertility by minimizing gonadotoxic medications, resulting in rates of infertility of less than 20\% [31]. In chronic myeloid leukemia, imatinib is not felt to impair future fertility, but pregnancies are not advised while taking this medication [33]. Data regarding future fertility with later-generation tyrosine kinase inhibitors are sparse. Regardless, there have been pregnancies reported while taking these medications $[41,42]$ so AYAs taking these medications should be counseled about the risk of becoming pregnant and to discuss fertility concerns with their treating physicians.

All of the hematological malignancies discussed above may require HSCT at some point along the disease trajectory, either early for high-risk diseases or later in the event of disease relapse. HSCT itself carries a high risk of infertility. Myeloablative preparation using total body irradiation has a subsequent rate of successful pregnancy of less than $3 \%$, while the overall rate of successful conception ranges from 0.6 to $11 \%$ depending on the study and preparative regimen used [43-47]. There is also a theoretical concern that pregnancy may lead to increased rates of disease relapse after HSCT due to the state of decreased immune surveillance, but this has not yet been clearly demonstrated by empirical data [33].

Finally, in contrast to problems with infertility are problems with unwanted fertility. If cancer patients are sexually active and do not desire pregnancy, they should be counseled that they must still use contraceptives and cannot rely on cancer treatment as a contraceptive itself [31].

\section{Psychosocial Care}

There is a recognized gap between the psychosocial needs of cancer patients and the services available to them [48]. On the supply side, very few pediatric or adult cancer centers have sufficient psychosocial support staff (e.g. social workers, psychologists, psychiatrists) with expertise in AYAs. Also lacking are centers with peer mentoring, support groups or counseling services for AYAs [9]. From a more patient-centered perspective, emotional barriers, poverty and underemployment due to illness, physical and functional limitations, and lack of knowl- 
edge can lead to underutilization of psychiatric services [49].

Psychosocial issues reported by AYAs with hematological malignancies include depression, anxiety, distress, delirium, posttraumatic stress disorder, sexual dysfunction, physical limitations, family dysfunction, strain on relationships, infertility, body image, problems with work, issues with education, hospital readmission, complications of treatment, slow recovery and other chronic issues $[15,48]$. Late effects of cancer treatment include problems with memory, learning, attention, cognition, social interactions and work performance [48]. Cancer patients use multiple coping mechanisms, most of which attempt to increase hope and give the patient a sense of control over his or her disease even though in reality many disease-related issues may be outside of the patient's control [48]. It may be helpful for providers to understand this, so they can appreciate how patients cope with these potentially fatal diagnoses.

To this end the National Comprehensive Cancer Network has included in its AYA guidelines a section on psychosocial issues to help clinicians address these issues [8]. Recommendations are mostly general rather than specific, but do include suggestions such as anticipatory education on the importance of medication adherence and early referral to mental health providers for psychiatric or cognitive dysfunction or signs of substance abuse. Church young adult groups and mentors can be useful allies for patients with crises of faith or conscience. In addition, there are a variety of face-to-face and virtual support groups that can act as adjunct support networks for AYAs. Finally, providers are encouraged to simplify treatment as much as possible and have some flexibility to account for non-disease-related obligations that patients may have.

\section{Access to Care and Socioeconomic Issues}

Despite the perception that AYAs are a generally healthy population, roughly one sixth suffer from some form of chronic illnesses and have trouble paying medical bills [7]. Access to care is paramount in order to cover the illnesses from which this group suffers including hematological malignancies [6]. Treatment of these diseases is complicated, requiring multidisciplinary care and significant social support. Leukemias and lymphomas are frequently treated at tertiary care hospitals, which may require patients to stay locally even if they live hours away.

In the USA, recent slow economic growth has depressed the job market, which in turn has led to difficul- ties obtaining adequate insurance [6]. As a subset, AYAs are the most uninsured population, which can lead to missed care opportunities and subsequent economic burdens including tradeoffs with education and career, using up savings, delinquency on loans, building up credit card debt, delaying moving out from their parents' home, increased cohabitation, delaying marriage and sometimes difficulty paying for basic necessities like rent and food $[6$, 50]. Even if one has adequate insurance at the time of diagnosis, there is the risk of losing insurance if there is loss of employment during treatment or - for dependent patients - the risk of aging out of eligibility for dependent insurance [6].

American AYAs suffer an increased interval from onset of symptoms to time of diagnosis. This does not seem to be affected by race, ethnicity, age, gender, marital status or surrogate measures of socioeconomic status, but is linked to underinsurance [10]. This delay can be as long as 13 weeks and lead to a more advanced stage of disease at the time of diagnosis [51]. Furthermore, at least one study showed that despite some popular belief, AYAs do tend to purchase insurance when offered by their employers [6]. For AYAs who are unemployed or whose parents are unemployed, the only other option is private health insurance. Employer-based health insurance tends to have subsidies to defray some of the cost to employees, but independently purchased insurance does not [52]. Moreover, premiums can increase seemingly arbitrarily, and preexisting conditions can be grounds for denial of coverage.

In an effort to make medical care more available to Americans, the Patient Protection and Affordable Care Act (PPACA) is being phased in and will establish among other things an insurance exchange system in which the federal government and each state will have programs available to health care consumers. Health exchanges will offer essential services that are important to hematological malignancy patients and will likely include ambulatory care, emergency room visits, hospitalization, psychiatric care, substance abuse, chronic diseases, prescriptions and rehabilitation [53]. Another benefit from which patients with hematological malignancies will benefit is the mandate that insurances will now cover any services that occur in the course of a clinical trial but would have been covered under routine care if that patient were not on trial [54].

Another important aspect of the PPACA is mitigation of health care costs, which are inflating at an unsustainable rate. One example of a cost-cutting measure being piloted by the government is bundling payments for a 
given diagnosis $[54,55]$. How this might work in the case of hematological malignancy is difficult to foresee due to the complex and multidisciplinary nature of the care involved. For instance, a lymphoma patient may see a surgeon, radiation oncologist and medical oncologist, and have multiple hospital admissions over a relatively short time both due to scheduled chemotherapy and complications of that therapy.

Two features of the PPACA, which will greatly impact access for AYAs and which are already in place, are the expansion of dependent insurance eligibility and the elimination of preexisting conditions. Prior to enactment, patients receiving insurance through their parents became disqualified for this option at the age of 19 or at the time of graduation from high school or college. Since September 23, 2010, all dependents are allowed to have dependent insurance until the age of $26[56,57]$. Evidence has shown that AYAs have taken advantage of this expansion of coverage $[6,58]$. While dependent insurance increased, Medicaid claims stayed stable and private selfinsurance decreased [57].

The elimination of preexisting conditions means that insurance companies and exchanges cannot deny patients because of their chronic medical conditions. In addition, the Department of Health and Human Services will review premium increases to make sure they are justified. The only variables on which issue of insurance and premiums can be based are age, geography, family versus individual status and tobacco use. Prior limitations on lifetime coverage for essential services and annual limitations on nonessential services which can both be a heavy burden to the oncology population are largely eliminated or phased out. Appeals against denials of coverage have also been made easier and will involve third parties that objectively review the cases.

\section{Conclusion}

AYAs with hematological malignancies are a unique population as defined not simply by their age and pathological diagnosis, but in terms of the challenges they face with regard to adequate access to medical care, representation on clinical trials, and short- and long-term treatment effects including altered fertility. There are efforts on national and international levels to better define and address these issues from both medical and social perspectives. In the meantime, it is the duty of the oncologists who treat these individuals to recognize this and to help these patients navigate treatment as best as possible. Resources available to clinicians include published guidelines specific to AYAs [8] and sites like ClinicalTrials.gov [59] to help patients and providers identify potential clinical trials that may result in better outcomes for individual patients and, eventually, the AYA community as a whole.

\section{References}

1 Bleyer A, O'Leary M, Barr R, Ries LAG (eds): Cancer Epidemiology in Older Adolescents and Young Adults 15-29 Years of Age, Including SEER Incidence and Survival: 19752000. NIH Publ No 06-5767. Bethesda, National Cancer Institute, 2006.

2 Bleyer A, Budd T, Montello M: Adolescents and young adults with cancer: the scope of the problem and criticality of clinical trials. Cancer 2006;107(suppl):1645-1655.

3 Surveillance, Epidemiology, and End Results (SEER) program: Seer*Stat database: incidence-SEER 13 Regs, public-use Nov 2004 sub for expanded races (1992-2002), National Cancer Institute, DCCPS, Surveillance Research Program, Cancer Statistics Branch, released April 2005, based on the November 2004 submission. www.seer.cancer.gov (accessed November 8, 2005).

4 Adolescents and young adults with cancer. Bethesda, National Cancer Institute at the National Institutes of Health, 2013. http:// www.cancer.gov/cancertopics/aya/reports (accessed July 31, 2013).
5 Wood WA, Lee SJ: Malignant hematologic diseases in adolescents and young adults. Blood 2011;117:5803-5815.

6 Collins SR, Garber T, Doty M: Young, uninsured, and in debt: why young adults lack health insurance and how the affordable care act is helping. Findings from the Commonwealth Fund Health Insurance Tracking Survey of young adults, 2011. Commonwealth Fund 2012;14:1-24.

7 Pulte $\mathrm{D}$, Gondos A, Brenner H: Trends in survival after diagnosis with hematologic malignancy in adolescence or young adulthood in the United States, 1981-2005. Cancer 2009; 115:4973-4979.

8 National Comprehensive Cancer Network: Adolescent and young adult (AYA) oncology (version 1.2012). http://www.nccn.org/professionals/physician_gls/pdf/aya.pdf (accessed May 25, 2013).

-9 Ramphal R, Meyer R, Schacter B, Rogers P, Pinkerton R: Active therapy and models of care for adolescents and young adults with cancer. Cancer 2011;117(suppl):2316-2322.
10 Bleyer A: Young adult oncology: the patients and their survival challenges. CA Cancer J Clin 2007;57:242-255.

-11 Liu L, Krailo M, Reaman GH, Bernstein L; Surveillance, Epidemiology and End Results Childhood Cancer Linkage Group: Childhood cancer patients' access to cooperative group cancer programs: a population-based study. Cancer 2003;97:1339-1345.

12 Bleyer A, Montello M, Budd T: Young adults with leukemia in the United States: lack of clinical trial participation and mortality reduction during the last decade. JCO Meeting Abstracts July 2004, vol 22, No 14, suppl 6623. http://meeting.ascopubs.org/cgi/content/abstract/22/14_suppl/6623.

13 Bleyer A, Budd T, Montello M: Older adolescents and young adults with cancer, and clinical trials: lack of participation and progress in North America; in Bleyer A, Barr R, Albritton K, Phillips M, Siegel S (eds): Cancer in Adolescents and Young Adults. New York, Springer, 2007, pp 71-81. 
14 Freyer DR, Felgenhauer J, Perentesis J; COG Adolescent and Young Adult Oncology Discipline Committee: Children's Oncology Group's 2013 blueprint for research: adolescent and young adult oncology. Pediatr Blood Cancer 2013;60:1055-1058.

15 Clinton-McHarg T, Paul C, Sanson-Fisher R, D'Este C, Williamson A: Determining research priorities for young people with haematological cancer: a value-weighting approach. Eur J Cancer 2010;46:3263-3270.

16 Effective Health Care Program: Helping you make better treatment choices: what is comparative effectiveness research. Rockville, Agency for Healthcare Research and Quality, US Department of Health and Human Services, 2013. http://www.effectivehealthcare.ahrq. gov/index.cfm/what-is-comparative-effectiveness-research1/ (accessed July 24, 2013).

17 Edge SB, Zwelling LA, Hohn DC: The anticipated and unintended consequences of the Patient Protection and Affordable Care Act on cancer research. Cancer J 2010;16:606-613

-18 Singal PK, Iliskovic N, Li T, Kumar D: Adriamycin cardiomyopathy: pathophysiology and prevention. FASEB J 1997;11:931-936.

-19 Sleijfer S: Bleomycin-induced pneumonitis. Chest 2001;120:617.

20 Mudie NY, Swerdlow AJ, Higgins CD, Smith P, Qiao Z, Hancock BW, Hoskin PJ, Linch DC: Risk of second malignancy after nonHodgkin's lymphoma: a British cohort study. J Clin Oncol 2006;24:1568-1574.

-21 Koontz MZ, Horning SJ, Balise R, Greenberg PL, Rosenberg SA, Hoppe RT, Advani RH: Risk of therapy-related secondary leukemia in Hodgkin lymphoma: the Stanford University experience over three generations of clinical trials. J Clin Oncol 2013;31:592-598.

-22 Pedersen-Bjergaard J, Andersen MK, Christiansen DH: Therapy-related acute myeloid leukemia and myelodysplasia after high-dose chemotherapy and autologous stem cell transplantation. Blood 2000;95:3273-3279.

23 Chemaitilly W, Sklar CA: Endocrine complications in long-term survivors of childhood cancers. Endocr Relat Cancer 2010;17:R141R159.

24 Chow E: Risk of thyroid dysfunction and subsequent thyroid cancer among survivors of acute lymphoblastic leukemia: a report from the Childhood Cancer Survivor Trial. Pediatr Blood Cancer 2009;53:432-437.

$\checkmark 25$ Brennan BM, Rahim A, Mackie EM, Eden OB, Shalet SM: Growth hormone status in adults treated for acute lymphoblastic leukaemia in childhood. Clin Endocrinol (Oxf) 1998; $48: 777-783$.

26 Fox S: E-patients with a disability or chronic disease. Washington, Pew Research Center, October 8, 2007. http://www.pewinternet.org/ Reports/2007/EpatientsWith-a-Disabilityor-Chronic-Disease.aspx (accessed July 31, 2013).
27 Fox S, Jones S: The social life of health information. Washington, Pew Research Center, June 2009. http://www.pewinternet.org/Reports/2009/8-The-Social-Life-of (accessed July 31,2013$)$.

28 Rainie L: Two-thirds of young adults and those with higher income are smartphone owners. Washington, Pew Research Center, September 11, 2012. http://www.pewinternet. org/Reports/2012/PIP_Smartphones_ Sept12\%209\%2010\%2012.pdf (accessed July 31, 2013)

29 Lee SJ, Schover LR, Partridge AH, Patrizio P, Wallace WH, Hagerty K, Beck LN, Brennan LV, Oktay K: American Society of Clinical Oncology recommendations on fertility preservation in cancer patients. J Clin Oncol 2006; 24:2917-2931.

-30 Tierney KD, Facione N, Padilla G, Blume K, Dodd M: Altered sexual health and quality of life in women prior to hematopoietic cell transplantation. Eur J Oncol Nurs 2007;11: 298-308.

31 Goodwin T, Oosterhuis EB, Kiernan M, Hudson MM, Dahl GV: Attitudes and practices of pediatric oncology providers regarding fertility issues. Pediatr Blood Cancer 2007;4:80-85.

32 Levine J, Canada A, Stern CJ: Fertility preservation in adolescents and young adults with cancer. J Clin Oncol 2010;28:4831-4841.

33 Jadoul P, Kim SS; ISFP Practice Committee: Fertility considerations in young women with hematological malignancies. J Assist Reprod Genet 2012;29:479-487.

34 The Ethics Committee of the American Society for Reproductive Medicine: Fertility preservation and reproduction in cancer patients. Fertil Steril 2005;83:1622-1628.

- 35 Loren AW, Mangu PB, Beck LN, Brennan L, Magdalinski AJ, Patridge AH, Quinn G, Wallace WH, Oktay K: Fertility preservation for patients with cancer: American Society of Clinical Oncology clinical practice guideline update. J Clin Oncol 2013;31:2500-2510.

36 ISPF Practice Committee, Kim SS, Donnez J, Barri P, Pellicer A, Patrizio P, Rosenwaks Z, Nagy P, Falcone T, Andersen C, Hovatta O, Wallace H, Meirow D, Gook D, Kim SH, Tzeng C, Suzuki S, Ishizuka B, Dolmans M: Recommendations for fertility preservation in patients with lymphoma, leukemia, and breast cancer. J Assist Reprod Genet 2012;29: 465-468.

37 Hodgson DC, Pintilie M, Gitterman L, Dewitt B, Buckley CA, Ahmed S, Smith K, Schwartz A, Tsang RW, Crump M, Wells W, Sun A, Gospodarowicz MK: Fertility among female Hodgkin lymphoma survivors attempting pregnancy following ABVD chemotherapy. Hematol Oncol 2007;25:11-15.

38 Sieniawski M, Reinecke T, Novoga L, Josting A, Pfisner B, Diehl V, Engert A: Fertility in male patients with advanced Hodgkin lymphoma treated with BEACOPP: a report of the German Hodgkin Study Group (GHSG). Blood 2008;111:71-76.
39 Behringer K, Mueller H, Goergen H, Thielen I, Eibl AD, Stumpf V, Wessels C, Wiehlpütz M, Rosenbrock J, Halbsguth T, Reiners KS, Schober T, Renno JH, von Wolff M, van der Ven K, Kuehr M, Fuchs M, Diehl V, Engert A, Borchmann P: Gonadal function and fertility in survivors after Hodgkin lymphoma treatment within the German Hodgkin Study Group HD13 to HD15 trials. J Clin Oncol 2013;31:231-239.

40 De Luyk N, Pozzato G, Ricci G, Tamaro P, Manno M, Tomei F, Trombetta C: Pre-treatment and posttreatment fertility in young male patients affected by Hodgkin and nonHodgkin lymphoma. Arch Ital Urol Androl 2012;84:141-145.

41 Conchon M, Sanabani SS, Bendit I, Santos FM, Serpa M, Dorliac-Llacer PE: Two successful pregnancies in a woman with chronic myeloid leukemia exposed to nilotinib during the first trimester of her second pregnancy: case study. J Hematol Oncol 2009;2:42.

42 Cole S, Kantarjian H, Ault P, Cortés JE: Successful completion of pregnancy in a patient with chronic myeloid leukemia without active intervention: a case report and review of the literature. Clin Lymphoma Myeloma 2009;9: 324-327.

43 Salooja N, Szydlo RM, Socie G, Rio B, Chatterjee R, Ljungman P, Van Lint MT, Powles R, Jackson G, Hinterberger-Fischer M, Kolb HJ, Apperly JF; Late Effects Working Party of the European Group for Blood and Marrow Transplantation: Pregnancy outcomes after peripheral blood or bone marrow transplantation: a retrospective survey. Lancet 2001; 358:271-276.

-44 Sanders JE, Pritchard S, Mahoney P, Amos D, Buckner CD, Witherspoon RP, Deeg HJ, Doney KC, Sullivan KM, Appelbaum FR: Growth and development following marrow transplantation for leukemia. Blood 1986;68:11291135.

45 Jadoul P, Anckaert E, Dewandeleer A, Steffens M, Dolmans MM, Vermylen C, Smitz J, Donnez J, Maiter D: Clinical and biologic evaluation of ovarian function in women treated by bone marrow transplantation for various indications during childhood or adolescence. Fertil Steril 2011;96:126-133.

46 Sanders JE, Hawley J, Levy W, Gooley T, Buckner CD, Deeg HJ, Doney K, Storb R, Sullivan K, Witherspoon R, Appelbaum FR: Pregnancies following high-dose cyclophosphamide with or without high-dose busulfan or total-body irradiation and bone marrow transplantation. Blood 1996;87:3045-3052.

47 Carter A, Robison LL, Francisco L, Smith D, Grant M, Baker KS, Gurney JG, McGlave PB, Weisdorf DJ, Forman SJ, Bhatia S: Prevalence of conception and pregnancy outcomes after hematopoietic cell transplantation: report from the Bone Marrow Transplant Survivor Study. Bone Marrow Transplant 2006;37: 1023-1029. 
48 Koehler M, Koenigsmann M, Frommer J: Coping with illness and subjective theories of illness in adult patients with haematological malignancies: systematic review. Crit Rev Oncol Hematol 2009;69:237-257.

49 Mosher CE, Duhamel KN, Rini CM, Li Y, Isola L, Labay L, Rowley S, Papadopoulos E, Moskowitz C, Scigliano E, Grosskreutz C, Redd WH: Barriers to mental health service use among hematopoietic SCT survivors. Bone Marrow Transplant 2010;45:570-579.

50 Fry R: Young adults after the recession: fewer homes, fewer cars, less debt. Washington, Pew Research Center, February 21, 2013. http://www.pewinternet.org/files/2013/02/ Financial_Milestones_of_Young_Adults_ FINAL_2-19.pdf (accessed July 31, 2013).
51 Martin S, Ulrich C, Munsell M, Taylor S, Lange G, Bleyer A: Delays in cancer diagnosis in underinsured young adults and older adolescents. Oncologist 2007;12:816-824.

52 Schwartz K, Claxton G: The Patient Protection and Affordable Care Act: how will it affect private health insurance for cancer patients? Cancer J 2010;16:572-576.

53 Hutchins VA, Samuels MB, Lively AM: Analyzing the Affordable Care Act: essential health benefits and implications for oncology. J Oncol Pract 2013;9:73-77.

54 Bailes JS, Kamin DY, Foster SE: The Patient Protection and Affordable Care Act: exploring the potential impact on oncology practice. Cancer J 2010;16:588-592.

55 Albright HW, Moreno M, Feeley TW, Walters R, Samuels M, Pereira A, Burke TW: The implications of the 2010 Patient Protection and Affordable Care Act and the Health Care and Education Reconciliation Act on cancer care delivery. Cancer 2011;117:1564-1574.
56 Bleyer WA: Potential favorable impact of the Affordable Care Act of 2010 on cancer in young adults in the United States. Cancer J 2010; 16:563-571.

57 Sommers BD, Buchmueller T, Decker SL, Carey C, Kronick R: The Affordable Care Act has led to significant gains in health insurance and access to care for young adults. Health Aff (Millwood) 2013;32:165-174.

58 Cantor J, Monheit A, DeLia D, Lloyd K: Early impact of the Affordable Care Act on health insurance coverage of young adults. Health Serv Res 2012;47:1773-1789.

59 ClinicalTrials.gov. Bethesda, National Institutes of Health, 2013. http://www.clinicaltrials.gov (accessed July 31, 2013). 